\title{
Neutralising Pathogens in Blood in Developing Countries - Thinking Outside the Screening Box
}

\author{
a report by \\ Gadi Borkow ${ }^{1}$ and Abdoulaye Doucoure ${ }^{2}$
}

1. Cupron Incorporated, Israel; 2. Pall Corporation, Port Washington

The safety of blood and its components continues to be a global problem More than two-thirds of the world does not have access to safe blood. Each year unsafe blood transfusions in developing countries result in eight to 16 million hepatitis B virus (HBV) infections, 2.3-4.7 million hepatitis C virus (HCV) infections and 80,000-160,000 HIV infections. ${ }^{2}$ A growing number of viral, bacterial and protozoa pathogens have been identified in blood products. New pathogens are regularly identified, ${ }^{3-5}$ as demonstrated by the West Nile virus (WNV) in the US6,7 and, more recently, by the Chikungunya virus in the Indian Ocean area.8,9

The combination of increased worldwide population immigration and ease of travel has allowed pathogens to constantly 'conquer' new territories. ${ }^{10-13}$ A good example is WNV, which was not present prior to 1999 in the western hemisphere, ${ }^{14}$ and is now present in the US, Mexico, Canada and Latin America.7,12,13,15 It is estimated that approximately one in 5,000 blood units were infected before the problem was even detected. ${ }^{16} \mathrm{~A}$ rapid series of centralised interventions in North America have been successful in significantly reducing and controlling the transmission of WNV through blood transfusions. ${ }^{17}$ Of particular concern is the silent emergence of a new agent with a prolonged latent period in which asymptomatic infected carriers donate blood and spread infection. Years may elapse from the discovery of an aetiological agent to the implementation of approved detection assays. Depending on the prevalence and infectivity of the agent in question, the delay can result in thousands of transfusion transmissions of the pathological agent. This was the case with HIV infection.

Bacterial contamination, particularly of platelet concentrates, and protozoa transmitted by blood components still represent sizeable risks in developed countries. Blood-borne bacterial pathogens are believed to contaminate between one per 100,000 and one per 1,000,000 units in the case of packed red blood cells (RBCs), and between one per 900 and one per 100,000 units of platelet concentrates. ${ }^{18}$ Platelet concentrates are stored at room temperature and are thus more susceptible to bacterial growth.

Mortality and morbidity associated with blood transfusions that have been contaminated by pathogens, especially in developing countries, have been well established. As an example, malaria is a principal cause of mortality in Africa and represents a major blood-borne disease. There is a high prevalence of transfusion-associated malaria infections through blood donation. ${ }^{19}$

$\mathrm{HCV}$ is also a major transfusion-transmitted infection (TTI) and occurs especially in developing countries. ${ }^{20}$ The risk of transmitting pathogens through blood transfusion in developing countries is very high, not only because many blood-borne pathogens are endemic, but also due to insufficient governmental awareness, funding, facilities and centralised educational and safety programmes. ${ }^{21}$ Infectious units will continue to elude screening and testing, as testing errors and product release errors are probably impossible to completely eliminate. Clear guidelines and regulations, followed by their stringent implementation by the relevant authorities, has significantly increased the safety of blood in many areas of the world. $22-25$

Blood centres in industrialised countries rigorously screen blood donations for known pathogens and have implemented nucleic acid testing, which further reduces pathogen transmission during the infectious window period (before serological conversion). The current risk of $\Pi \mathrm{Tl}$ is constantly being reduced. ${ }^{26}$ Calculated residual risks of transfusion-transmitted viruses in repeat US blood donors are approximately one in two million for HIV and HCV, one in 144,000 to 500,000 for HBV and one in 641,000 for human T-lymphotropic virus-1 and -2 (HTLV-I and HTLV-II).27,28 The residual risk of receiving a bacterially contaminated platelet component, with clinical consequences, is estimated at approximately one in 75,000 if culturenegative and one in 33,000 if not tested by culture methods. ${ }^{28}$ Risks are estimated to be even lower in Europe. ${ }^{29}$ However, in many developing countries, where the prevalence of viral and other pathogen infections among blood donors is greater than in industrialised countries, the blood supply is either incompletely or barely screened for pathogens. ${ }^{30-33}$ The risk of transfusion-transmitted pathogens is significantly higher. ${ }^{34}$ Many pathogens that have the potential to invade the blood supply are not screened because of low prevalence in the general population or the lack of readily available tests for the agent.. ${ }^{27}$ The risk of nosocomial viral transmissions in blood banks is also a significant hazard. ${ }^{35}$

There are three main approaches used to identify and prevent the use of contaminated blood collected for the purpose of transfusion: prevention, detection and inactivation. The use of these three approaches is not mutually exclusive. Prevention includes the epidemiological control of donor populations, donor education, donor selection and safety procedures (i.e. proper skin preparation prior to transfusion). It also may

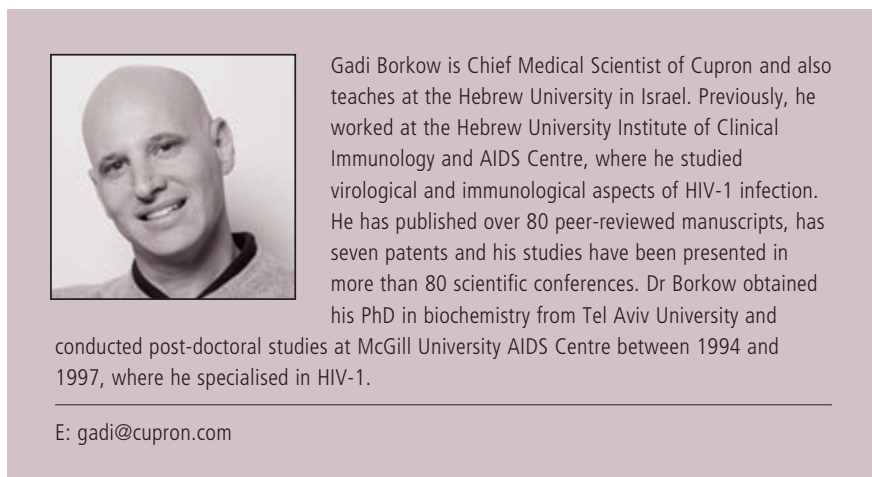


involve diverting the collected blood to a temporary storage container where detection and/or inactivation procedures are conducted before the blood or its components are stored in their final storage containers. The safety of blood supplies has been significantly improved in some countries by the selection of non-remunerated voluntary donors who are at low risk of TTIs. ${ }^{36}$

Epidemiological control and other prevention techniques, while carefully implemented in developed countries, may be problematic (if not absent) in many developing countries. This may be due to a high number of misinformed donors and poor staff training in donor management. ${ }^{37}$

More than two-thirds of the world does not have access to safe blood.

Even in cases where the donors belong to a low-risk blood donor group the rates of seroprevalence for pathogens may be high in pathogenendemic areas. ${ }^{38}$

Detection relies on identifying the pathogens in blood as a way to avoid the use of contaminated units. Technologies use nucleic acid amplification testing (NAT), bacterial culture, bacterial fluorescent probes and serological and biochemical tests to detect pathogen proliferation. HBV, HCV, HIV, parvovirus B19, HTLV I/II and Treponema palladium are regularly being tested for in donated blood units in developed countries. ${ }^{39-42}$ Other pathogen screening conducted on an 'as-needed' basis are cytomegalovirus, malaria and Trypanosoma cruzi. ${ }^{10}$ The introduction of NAT systems for the detection of viral genomes has significantly reduced contamination frequency. ${ }^{41}$ An example of this reduction is the residual risk of post-transfusion hepatitis reduction to as low as one in $100,000.43$

Detection procedures have their own difficulties. One of these is the documented problem of determining the existence of contaminated blood during the pre-seroconversion period of infection. Highly sensitive detection tests, such as individual or mini-pool NAT, reduce but do not eliminate this period of potential infectivity. ${ }^{44,45}$ The amount of time and the high cost required for such testing make single-unit NAT testing on a large scale infeasible.

Other detection methods that require seroconversion do not have the sensitivity to determine the presence of HIV or HCV during the preseroconversion stage of viral infections. In countries where the endemic rates of many pathogens are high, the residual risk of TTI, in spite of careful blood screening, is still high (e.g. Brazil).46

Bacterial contamination, which occurs in platelet concentrates, is screened by using the most sensitive method available, which has a sensitivity of less than $40 \%$ due to the low numbers of bacteria during the initial contamination periods. ${ }^{47}$ More sensitive detection methods are constantly being developed and improved. 48,49 In 2005, the US-based Pall Corporation developed the first technology allowing a transfusion-ready therapeutic dose of whole-blood-derived platelets. This system provides leukocyte-reduced platelets that are bacteria-tested via a highly sensitive culture technique that detects over $99 \%$ of bacterial infection. ${ }^{50}$

A third approach is to inactivate and/or remove pathogens in contaminated units of donated blood or blood products.,27,51 Although the acceptable 'log reduction' number for a given organism is not standardised, experience suggests that fewer than four log reductions may be insufficient and greater than six log reductions sufficient. ${ }^{27} \mathrm{~A}$ target to reduce the infectious titres of pathogens by five logs in blood and blood components has been set by the US Food and Drug Administration (FDA). ${ }^{52}$ The challenge of pathogen inactivation in blood is to reduce the level of pathogen infectivity without significantly compromising the key essential cellular or protein components or introducing some new toxicity, carcinogenicity or teratogenicity. ${ }^{27}$

Solvent detergent (SD) treatment has been successfully applied with pooled plasma during the last 20 years. The solvent detergent destroys 'enveloped' viruses including HIV-1, HIV-2, HCV, HBV and HTLV-l/II. It does not destroy 'non-enveloped' viruses such as parvovirus and the hepatitis A virus. The detergents need to be removed by either oil extraction or chromatographic adsorption. In addition to being ineffective against non-enveloped viruses, SD plasma has been implicated in patient death and has caused at least 16 deaths due to SD plasma-induced blood clots. ${ }^{53}$ SD treatment also results in some loss of crucial plasma proteins: $\alpha 2$-antiplasmin and protein-S. These concerns, along with economic factors, resulted in the removal of SD plasma from the US market. SD plasma is still used widely in Europe. Due to the above concerns, and the need to effectively remove the detergents used from the plasma and plasma components (a burdensome and expensive procedure), the effectiveness and safety of SD treatment on a routine basis in developing countries is questionable.

Other inactivation procedures, such as pasteurisation and dry-heat application, are effective in inactivating 'enveloped' and 'non-enveloped' viruses (e.g. HAV and the B19 virus). ${ }^{54}$ These procedures are used for isolated blood proteins, such as albumin or clotting factors. Since protein denaturation occurs, stabilisers need to be introduced (and later removed), making these procedures expensive and cumbersome, and under some conditions they do not achieve complete viral inactivation. ${ }^{27}$

Most other inactivation approaches use chemicals that target the nucleic acids of pathogens. ${ }^{27}$ The blood products that the chemicals are added to are then subjected to ultraviolet (UV) radiation. It causes the compounds to link to the pathogen's nucleic acids, preventing their replication. Methylene blue-light treatment of single-donor plasma units has a similarly long track record to pooled SD-treated plasma. This method is less documented and also has a greater affect on coagulation factors. ${ }^{3}$

Psoralen light-treated plasma has recently been introduced to Europe. The method of riboflavin light treatment of plasma is still being developed. Some reduction of coagulation factor activity occurs and the removal of excess compounds and by-products is needed to avoid potential toxicity. Psoralen and riboflavin light treatment for platelets have been approved for use in Europe and for clinical trials in the US. Photochemical treatments affect platelet activity. ${ }^{55}$ Pathogen reduction of RBCs with other compounds, such as frale (S-303) or inactine (PEN110), has so far resulted in the formation of auto-antibodies, and until the immunoreactivity and 
immunogenicity of these highly effective pathogen inactivation compounds are both investigated further and resolved, their usage in blood banking is uncertain. All of these methods require the introduction of chemicals into the blood. Their toxicity or mutagenicity potential has not been fully determined. In many cases the determination of the dangers from the photodecomposition products of these chemicals has not been evaluated. Additionally, the exposure of blood components to UV or other radiation may also be harmful in ways not yet assessed. ${ }^{56}$ All of these pathogen-neutralisation technologies are expensive and cannot be easily and practically implemented in many developing countries.

The development of safe, inexpensive and easy-to-implement approaches to inactivate or remove a broad spectrum of pathogens is highly desirable. One such approach may be the use of devices that filter out and/or deactivate the pathogens in whole blood or blood products during their passage through the device. One such device uses micro-porous filters capable of removing large particles, such as viruses, in plasma and plasma products. 57,58 This technology is based on filter pore size. Most viruses range in size from approximately 20 to $200 \mathrm{~nm}$, and membranes used in these micro-porous filters have a pore size of 15 to $40 \mathrm{~nm}$. Nano-filtration typically results in a four- to six-log removal of most viruses, with a $90-95 \%$ recovery rate of protein activity. ${ }^{27}$ Removal of small non-enveloped viruses by antibodyenhanced nano-filtration during the manufacture of plasma derivatives is being explored. ${ }^{59}$ Two significant problems with nano-filtration are the high operating pressure (typically between 100 and 150 pounds per square inch [psi]) and protein fouling, which can severely limit the membrane capacity and may even contribute to incomplete virus retention.

Ultra-filtration (UF) membranes, with a pore size of 1 to $100 \mathrm{~nm}$, are increasingly being used in the biopharmaceutical industry. These commercial polymeric membranes are typically hydrophilic and can remove $99.9 \%$ of virus particles from the feed stream. ${ }^{50,60}$ Despite an improved protein-fouling resistance, UF membrane technology requires 30-50psi of operating pressure, and the virus removal efficiency may be insufficient for blood applications.

A durable platform technology was recently developed. It introduces copper oxide into polymeric materials, empowering them with potent broad-spectrum antibacterial, antifungal and antiviral properties.61,62 By using this technology, copper-oxide-containing devices have been shown to drastically reduce infectious titres of a panel of viruses spiked into culture media, including enveloped, non-enveloped, RNA and DNA viruses. ${ }^{63,64}$ This suggests the possibility of using these devices to deactivate a wide spectrum of infectious viruses found in filterable suspensions. Copper neutralisation of infectious bronchitis virus, poliovirus, HIV-1 and other enveloped or non-enveloped, single- or double-stranded DNA or RNA viruses has previously been reported. ${ }^{65}$ Copper can inactivate viruses by damaging their genetic materials, envelope and/or key proteins. 65 It has been demonstrated that the HIV-1 protease, essential for the replication of the virus, is inhibited by stoichiometric concentrations of copper ions. ${ }^{66}$

The biochemistry of copper in humans has long been studied and understood. ${ }^{67}$ Excess copper in humans, at the levels 'leached' out into the blood or plasma as it passes through such devices (less than $2 \mu \mathrm{g} / \mathrm{dl}$ ), is not toxic. This represents only a minor perturbation to the normal serum levels of copper in blood, which ranges from 80 to $160 \mu \mathrm{g} / \mathrm{dl} .{ }^{68,69}$ As a relatively benign trace element, humans adapt to changes in copper intake, retaining more at low intakes and absorbing less and excreting more at higher intakes. ${ }^{70}$ Sufferers of Wilson's disease and Menkes syndrome, two well-known diseases involving defective copper metabolism, have mean levels of blood-copper concentrations of about 525 and $<70 \mu \mathrm{g} / \mathrm{dl}$, respectively. Normally, any excess copper absorbed by

Using human blood, especially in developing countries where blood-borne pathogens are endemic, poses significant safety concerns.

the body is readily secreted. ${ }^{71}$ Due to its cost-effectiveness and speed of use, filtration with copper-based devices can be used as a back-up to, and in conjunction with, nano-filters and any detection methods bloodsupply managers may choose to employ.

\section{Conclusions}

Until alternative safe and effective solutions for the use of blood and blood components for medical treatment are developed, the use of allogeneic blood in numerous medical disorders and emergencies will continue. Using human blood, especially in developing countries where blood-borne pathogens are endemic, poses significant safety concerns.

Implementation of safety measures, such as donor selection, staff training and the use of sterile equipment, is highly desirable. The execution of careful screening of blood for the presence of pathogens would significantly reduce the risk of TTIs in developing countries, as is the case in the developed countries. However, the incidence of infected individuals is so high in many of these areas that little blood would be available if all 'marker-positive' donors were excluded.27

New pathogens continue to emerge. A wide-spectrum technology, or a combination of technologies, that can widely neutralise pathogens could confer the desired protection and may eliminate the need for blood screening, which is too expensive to perform regularly. The implementation of the current modalities of pathogen inactivation, which further reduce the residual risk of TTI, is not practical and achievable in many of the developing countries. They significantly increase the cost of blood units and also require sophisticated equipment that needs infrastructure, constant maintenance and trained personnel.

In many developing areas of the world, where infections are rampant and blood transfusions are highly risky, cheap, one-time-usage, disposable and wide-spectrum pathogen removal/inactivation devices would be realistic. One such device could be a small filter containing a nanomembrane combined with a copper-oxide biocidal layer filter. These devices may be attached to the blood transfusion containers, or to the containers containing the blood fractions. The whole blood or blood component would pass through it by simple gravitational force. The safety of such devices has to be carefully studied and determined.

While some damage may occur to key components of the blood, and some of these simple devices may be used with some blood components 
and not with others (e.g. with plasma and platelets, but not with RBCs), the benefit of using such devices on a routine basis should be carefully considered vis à vis the risk of blood or blood products pathogen contamination. The feasibility of their usage may vary for different locations. While the damage to the blood components may outweigh the benefit of using it in blood centres where careful pathogen screening is conducted and pathogens are not endemic, in many developing and poor areas - where the prevalence of pathogens is high, blood screening is lacking or not economically and practically feasible and the risk of contaminated blood donations is extremely high - thinking outside the screening box and using inexpensive, easy-to-use pathogen neutralisation/removal devices, should be considered.
1. World Health Organization, Fact sheets. Blood safety and volunteer donations, 2006

2. Anon, Blood supply and demand, Lancet, 2005;365:2151.

3. Solheim BG, Pathogen reduction of blood components, Transfus Apher Sci, 2008:39:75-82.

4. Dodd RY, Emerging infections and global blood safety, Dev Biol (Basel), 2007;127:237-48.

5. Alter HJ, Stramer SL, Dodd RY, Emerging infectious diseases that threaten the blood supply, Semin Hematol, 2007:44:32-41.

6. Busch MP, Wright DJ, Custer B, et al., West Nile virus infections projected from blood donor screening data, United States, 2003, Emerg Infect Dis, 2006:12:395-402.

7. Stramer SL, Fang CT, Foster GA, et al., West Nile virus among blood donors in the United States, 2003 and 2004, N Engl J Med 2005;353:451-9.

8. Simon F, Parola P, Grandadam M, et al., Chikungunya infection: an emerging rheumatism among travelers returned from Indian Ocean islands. Report of 47 cases, Medicine (Baltimore), 2007;86:123-37.

9. Parola P, de LX, Jourdan J, et al., Novel chikungunya virus varian in travelers returning from Indian Ocean islands, Emerg Infect Dis, 2006;12:1493-9.

10. Piron M, Verges M, Munoz J, et al., Seroprevalence of Trypanosoma cruzi infection in at-risk blood donors in Catalonia (Spain), Transfusion, 2008; in press.

11. Hochedez $P$, Hausfater $P$, Jaureguiberry $S$, et al., Cases of chikungunya fever imported from the islands of the South West Indian Ocean to Paris, France, Euro Surveill, 2007:12.

12. Centers for Disease Control and Prevention, Detection of West Nile virus in blood donations_-Puerto Rico, 2007, MMWR Morb Mortal Wkly Rep, 2008:57:577-80.

13. Sanchez-Guerrero SA, Romero-Estrella S, Rodriguez-Ruiz A, et al. Detection of West Nile virus in the Mexican blood supply, Transfusion, 2006;46:111-17

14. Hollinger FB, Kleinman S, Transfusion transmission of West Nile virus: a merging of historical and contemporary perspectives, Transfusion, 2003;43:992-7.

15. Cameron C, Reeves J, Antonishyn N, et al., West Nile virus in Canadian blood donors, Transfusion, 2005:45:487-91.

16. Biggerstaff BJ.,Petersen LR, Estimated risk of West Nile virus transmission through blood transfusion during an epidemic in Queens, New York City, Transfusion, 2002;42:1019-26.

17. Stramer SL, Reacting to an emerging safety threat: West Nile virus in North America, Dev Biol (Basel), 2007:127:43-58.

18. Walther-Wenke $G$, Incidence of bacterial transmission and transfusion reactions by blood components, Clin Chem Lab Med, 2008:46:919-25.

19. Tayou TC, Mbanya D, Garraud O, et al., Blood safety: malaria and blood donation in Africa, Transfus Clin Biol, 2007;14:481-6.

20. Prati $D$, Transmission of hepatitis $C$ virus by blood transfusions and other medical procedures: a global review, J Hepatol, 2006;45:607-16.

21. Ahmed SG, Ibrahim UA, Hassan AW, Adequacy and pattern of blood donations in north-eastern Nigeria: the implications for blood safety, Ann Trop Med Parasitol, 2007:101:725-31.

22. Whyte $G$, Improved safety of clinical blood transfusion in four provinces of China 1997-2005, Dev Biol (Basel), 2007;127:197-204.

23. Zhu YM, Blood safety — a focus on plasma derivatives in Mainland China, Dev Biol (Basel), 2007;127:175-81.

24. Tadokoro K, The new Japanese blood law: its impact on blood safety and usage, Dev Biol (Basel), 2007;127:161-8.

25. Seitz $R$, The European Blood Directive - its role in blood safety, Dev Biol (Basel), 2007;127:147-52.

26. Dodd RY, Current risk for transfusion transmitted infections, Curr Opin Hematol, 2007;14:671-6.

27. Bryant BJ, Klein HG, Pathogen inactivation: the definitive safeguard for the blood supply, Arch Pathol Lab Med 2007;131:719-33.
28. Stramer SL, Current risks of transfusion-transmitted agents: a review, Arch Pathol Lab Med, 2007;131:702-7.

29. Pillonel J, Laperche $S$, Trends in risk of transfusion-transmitted viral infections (HIV, HCV, HBV) in France between 1992 and 2003 and impact of nucleic acid testing (NAT), Euro Surveill, 2005;10:5-8.

30. Moore A, Herrera G, Nyamongo J, et al., Estimated risk of HIV transmission by blood transfusion in Kenya, Lancet, 2001;358:657-60

31. Chatterjee R, Tarwater P, Neogi D, et al., Estimation of HIV seroprevalence in blood bank camps in Kolkata, India, Transfus Med, 2004;14:77-8.

32. Diro E, Alemu S, Yohannes A, Blood safety \& prevalence of transfusion transmissible viral infections among donors at the Red Cross Blood Bank in Gondar University Hospital, Ethiop Med J, 2008:46:7-13.

33. Tagny CT, Mbanya D, Tapko JB, et al., Blood safety in SubSaharan Africa: a multi-factorial problem, Transfusion, 2008:48:1256-61.

34. Shang $G$, Seed $C R$, Wang F, et al., Residual risk of transfusiontransmitted viral infections in Shenzhen, China, 2001 through 2004, Transfusion, 2007;47:529-39.

35. Ganczak M.Barss P, Nosocomial HIV infection: epidemiology and prevention—a global perspective, AIDS Rev, 2008;10:47-61.

36. Polizzotto MN, Wood EM, Ingham $\mathrm{H}$, et al., Reducing the risk of transfusion-transmissible viral infection through blood donor selection: the Australian experience 2000 through 2006, Transfusion, 2008:48:55-63.

37. Nebie KY, Olinger CM, Kafando E, et al., Lack of knowledge among blood donors in Burkina Faso (West Africa); potential obstacle to transfusion security, Transfus Clin Biol, 2007; 14:446-52.

38. Egah DZ, Banwat EB, Audu ES. et al., Hepatitis B surface antigen, hepatitis $\mathrm{C}$ and HIV antibodies in a low-risk blood dono group, Nigeria, East Mediterr Health J, 2007;13:961-6.

39. Velati $C$, Romano $L$, Fomiatti $L$, et al., Impact of nucleic acid testing for hepatitis B virus, hepatitis C virus, and human immunodeficiency virus on the safety of blood supply in Italy: a 6year survey, Transfusion, 2008, in press.

40. Montag T, Strategies of bacteria screening in cellular blood components, Clin Chem Lab Med, 2008;46:926-32.

41. Nubling CM, Unkelbach U, Chudy M, et al., Effect of viral nucleic acid testing on contamination frequency of manufacturing plasma pools, Transfusion, 2008:48:822-6.

42. Schmidt M, Themann A, Drexler C, et al., Blood donor screening for parvovirus B19 in Germany and Austria, Transfusion, 2007;47:1775-82

43. Shimoyama R, Transfusion-transmitted diseases, Hokkaido Igaku Zasshi, 2008;83:5-21.

44. Kretzschmar E, Chudy M, Nubling CM, et al., First case of hepatitis C virus transmission by a red blood cell concentrate after introduction of nucleic acid amplification technique screening in Germany: a comparative study with various assays, Vox Sang, 2007:92:297-301.

45. Shan $\mathrm{H}$, Ren FR, Zhao HY, et al., A multi-Chinese blood center study testing serologic-negative donor samples for hepatitis C virus and human immunodeficiency virus with nucleic acid testing, Transfusion, 2007:47:2011-16.

46. Maresch C, Schluter PJ, Wilson AD, et al., Residual infectious disease risk in screened blood transfusion from a high-prevalence population: Santa Catarina, Brazil, Transfusion, 2008;48:273-81.

47. Murphy WG, Foley M, Doherty C, et al., Screening platelet concentrates for bacterial contamination: low numbers of bacteria and slow growth in contaminated units mandate an alternative approach to product safety, Vox Sang, 2008, in press.

48. Dreier J, Stormer M, Kleesiek K, Real-time polymerase chain reaction in transfusion medicine: applications for detection of bacterial contamination in blood products, Transfus Med Rev, 2007:21:237-54
49. Kwon JA, Lee $\mathrm{H}$, Lee $\mathrm{KN}$, et al., High diagnostic accuracy of antigen microarray for sensitive detection of hepatitis $\mathrm{C}$ virus infection, Clin Chem, 2008;54:424-8.

50. Ross $A$, Yomtovian R, Breakthrough technology from Pall increases platelet availability and safety, 2005. Available at: www.pall.com/news_articles_38333.asp

51. McCullough J, Pathogen inactivation: a new paradigm for preventing transfusion-transmitted infections, Am I Clin Pathol, 2007;128:945-55

52. FDA Workshop, Minutes of Safety and Efficacy of Methods for Reducing Pathogens in Cellular Blood Products Used in Transfusion, 2003

53. Grady D, Doctors are cautioned not to give a type of plasma to liver patients, New York Times, 2002.

54. Jorquera JI, Safety procedures of coagulation factors, Haemophilia, 2007;13(Suppl. 5):41-6

55. Apelseth TO, Bruserud O, Wentzel-Larsen T, et al., In vitro evaluation of metabolic changes and residual platelet responsiveness in photochemical treated and gamma-irradiated single-donor platelet concentrates during long-term storage, Transfusion, 2007;47:653-65

56. National Institute of Environmental Health Sciences, Nationa Toxicity Program Report on Carcinogen, 2002, 10th report on carcinogens: Research Triangle Park, NC, US.

57. Yokoyama T, Murai K, Murozuka T, et al., Removal of small nonenveloped viruses by nanofiltration, Vox Sang, 2004;86:225-9.

58. Burnouf T.,Radosevich M, Nanofiltration of plasma-derived biopharmaceutical products, Haemophilia, 2003:9:24-37.

59. Kreil TR, Wieser A, Berting A, et al., Removal of small nonenveloped viruses by antibody-enhanced nanofiltration during the manufacture of plasma derivatives, Transfusion, 2006;46:1143-51.

60. Allegrezza A, Ireland T, Kools W, Membranes in the Biopharmaceutical Industry, In: Peinemann KV and Pereira-Nunes $S$ (eds), Membranes for Life Sciences, Weinheim (GmbH): WileyVCH, 2008;4-91.

61. Borkow G.,Gabbay J, Putting copper into action: copperimpregnated products with potent biocidal activities, FASEB 2004;18:1728-30

62. Gabbay J, Mishal J, Magen E, et al., Copper oxide impregnated textiles with potent biocidal activities, Journal of Industrial Textiles, 2006;35:323-35.

63. Borkow G, Sidwell RW, Smee DF, et al., Neutralizing viruses in suspensions by copper oxide based filters, Antimicrob Agents Chemother, 2007;51:2605-7.

64. Borkow G, Lara HH, Covington CY, et al., Deactivation of human immunodeficiency virus type 1 in medium by copper oxidecontaining filters, Antimicrob Agents Chemother, 2008:52:518-25.

65. Borkow G., Gabbay J, Copper as a biocidal tool, Curr Med Chem 2005; 12:2163-75

66. Karlstrom AR.,Levine RL, Copper inhibits the protease from human immunodeficiency virus 1 by both cysteine-dependent and cysteine-independent mechanisms, Proc Natl Acad Sci US A, 1991:88:5552-6.

67. Turnlund JR, Human whole-body copper metabolism, Am J Clin Nutr, 1998;67:960S-964S

68. Ahmed MJ, Jahan I, Banoo S, A simple spectrophotometric method for the determination of copper in industrial, environmental, biological and soil samples using 2,5-dimercapto-1,3,4-thiadiazole, Anal Sci, 2002;18:805-10.

69. Yilmaz ME, Kiraz M, Kara IH, The evaluation of serum zinc and copper levels in hemodialysis patients in Southeast Turkey, Dial Transplant, 2000;29:718-21.

70. Linder $\mathrm{M}$, Biochemistry and molecular biology of copper in mammals, 2002:1-32.

71. Massaro EJ (ed), Handbook of copper pharmacology and toxicology, Totowa, NJ: Humana Press, 2002. 